\title{
Greve e ética na Universidade
}

Otavio Pinto e Silva ${ }^{I}$

GREVE é um fato social e como tal pode ser valorada de diferentes modos
pelo direito, a depender do contexto político vigente e da opção feita
pelo ordenamento jurídico.

Analisada sob uma perspectiva negativa e reducionista, diante do prejuízo que causa às atividades produtivas e às relações sociais, a greve já foi classificada até como delito: em 1937, por exemplo, a Constituição do Estado Novo a declarou um recurso antissocial, nocivo ao trabalhador e ao capital e incompatível com os superiores interesses da produção nacional.

Em outros momentos, defendeu-se uma concepção da greve como uma liberdade, que não poderia estar sujeita a qualquer condicionamento e, portanto, deveria ser independente de lei, cabendo ao legislador se abster de regular o tema. A greve se justificaria por si mesma, e o Estado deveria ser indiferente a ela.

Modernamente, a greve passou a ser reconhecida como um fato socialmente útil, a ponto de o ordenamento jurídico a conceber como um direito, a ser protegido e garantido, mas também sujeito a limitações.

Com efeito, a greve hoje deve ser examinada sob a perspectiva da atuação coletiva dos trabalhadores, de paralisação das atividades produtivas como uma maneira de exteriorizar a insatisfação com as condições de trabalho, a fim de forçar a negociação e o atendimento de reivindicações, em um contexto democrático.

Já se afirmou que “a greve exerce uma pressão necessária que leva à reconstrução do direito do trabalho quando as normas vigentes não atendem às exigências do grupo social. Força o empregador a fazer concessões que não faria de outro modo. Obriga o legislador a se manter vigilante e reformular a ordem jurídica. Logo, apesar dos seus inconvenientes, a greve é necessária e compatível com as estruturas capitalistas" (Nascimento, 1992, p.633).

O direito do trabalho é um ramo do direito que se caracteriza pela pluralidade de fontes de criação de normas jurídicas: o Estado legisla sobre matéria trabalhista, mas os particulares também podem exercer o poder de autorregulamentação de seus próprios interesses, por meio da negociação coletiva.

Sendo assim, a garantia do direito de greve se mostra como uma medida indispensável à sustentação da negociação coletiva, eis que tem como objetivo fundamental estabelecer o equilíbrio de forças no desenrolar do processo negocial.

Nesse aspecto, o texto da Constituição de 1988 é bastante preciso, ao prever a greve como um direito dos trabalhadores e dizer que compete a eles decidir sobre a oportunidade de exercê-lo e sobre os interesses que devam por meio dele defender. 
Cumpre ressaltar a dificuldade de harmonizar esse direito com outros constitucionalmente previstos, especialmente quando os movimentos paredistas atingem os chamados serviços essenciais, capazes de causar prejuízos não somente ao empregador, mas também à sociedade.

$\mathrm{Na}$ ordem democrática a greve precisa ser aceita como um instrumento legítimo, de modo que os limites ao seu exercício somente podem ser admitidos quando estiverem em jogo interesses da sociedade.

A noção básica a trabalhar, fixada pela própria Constituição $\left(\operatorname{artigo} 9^{\circ}, \mathfrak{S}\right.$ $2^{\circ}$ ), é a do abuso de direito, podendo ser enunciada como o princípio da responsabilidade: no exercício do direito de greve, os responsáveis por eventuais abusos devem ser punidos na forma da lei.

A Lei n.7.783/89 regulamenta a questão; porém, exige uma série de formalidades burocráticas para a deflagração dos movimentos grevistas e dispõe, no artigo 14, que constitui abuso de direito a simples inobservância das normas nela contidas.

Com isso, os Tribunais Trabalhistas se especializaram em julgar a "abusividade" de greves, levando em conta a mera desobediência a aspectos formais, o que na prática serve como uma maneira de enfraquecer a posição dos trabalhadores.

No Estado Democrático de Direito, a apuração de eventuais abusos de ordem civil, penal e trabalhista, quando do exercício do direito de greve, deve ser efetuada em processos regulares (à luz do contraditório e da ampla defesa), para a punição dos responsáveis, mas nunca para simplesmente forçar os trabalhadores a encerrar uma greve, mesmo que esta esteja causando prejuízos e desconforto.

A responsabilidade civil pelos danos materiais causados é uma forma de reparação do abuso de direito praticado pelo sindicato ou pelos grevistas; a punição penal é um modo de responsabilizar o autor de ilícitos criminais; a dispensa por justa causa é uma sanção trabalhista a que se sujeita o trabalhador pelos excessos que praticar.

A greve gera debates carregados de emoção, sendo certo que, no Brasil, frequentemente a mídia passa uma imagem de que ela é coisa de baderneiros, arruaceiros, vagabundos. Mas em verdade trata-se de um instrumento indispensável para a defesa dos interesses dos trabalhadores durante o processo de negociação coletiva: é o mais importante meio de ação direta de que esses dispõem para fazer o empregador ouvir suas reivindicações laborais.

Curioso, no entanto, que passados 25 anos de vigência da Constituição ainda não tenha sido regulamentado o exercício do direito de greve no setor público.

A citada Lei n.7.783/89 foi promulgada em 28 de junho de 1989, antes que a nova ordem constitucional completasse um ano, mas voltou-se apenas ao setor privado: afinal, o artigo 37 da Constituição assegurou a greve aos servido- 
res públicos mas exigiu que o seu exercício fosse devidamente regulamentado, para levar em conta as peculiaridades de uma ação coletiva dos trabalhadores que pudesse atingir as atividades do Estado.

Em 1998 foi aprovada a emenda constitucional n.19, de iniciativa do governo do presidente Fernando Henrique Cardoso, para ressaltar que o direito de greve dos servidores públicos seria exercido nos termos e nos limites definidos em lei específica, a ser debatida e aprovada pelo Congresso Nacional.

Diante da omissão de nossos parlamentares em aprovar tal lei, o Supremo Tribunal Federal foi provocado, por meio de um mandado de injunção, a se manifestar sobre o tema. A ação foi proposta pelo Sindicato dos Trabalhadores do Poder Judiciário do Estado do Pará (Sinjep) e foi julgada em 25 de outubro de 2007, tendo sido o seu relator o ministro Eros Grau (MI 712).

Trata-se de decisão muito importante, pois reconheceu que incumbe ao Poder Judiciário produzir a norma suficiente para tornar viável o exercício do direito de greve dos servidores públicos, consagrado no artigo 37 da Constituição. Veja-se a seguir alguns itens que constaram da ementa do Acórdão proferido no julgamento.

Mandado de Injunção. Art. $5^{\circ}$, LXXI da Constituição do Brasil. Concessão de efetividade à norma veiculada pelo artigo 37 , inciso VII, da Constituição do Brasil. Legitimidade ativa de entidade sindical. Greve dos trabalhadores em geral (art. $9^{\circ}$ da Constituição do Brasil). Aplicação da lei federal n.7.783/89 à greve no serviço público até que sobrevenha lei regulamentadora. Parâmetros concernentes ao exercício do direito de greve pelos servidores públicos definidos por esta corte. Continuidade do serviço público. Greve no serviço público. Alteração de entendimento anterior quanto à substância do mandado de injunção. Prevalência do interesse social. Insubsistência do argumento segundo o qual dar-se-ia ofensa à independência e harmonia entre os poderes (art. $2^{\circ}$ da Constituição do Brasil) e à separação dos poderes (art. $60, \mathbb{4} 4^{\circ}$, III, da Constituição do Brasil). Incumbe ao Poder Judiciário produzir a norma suficiente para tornar viável o exercício do direito de greve dos servidores públicos, consagrado no artigo 37, VII, da Constituição do Brasil.

1. O acesso de entidades de classe à via do mandado de injunção coletivo é processualmente admissível, desde que legalmente constituídas e em funcionamento há pelo menos um ano. 2. A Constituição do Brasil reconhece expressamente possam os servidores públicos civis exercer o direito de greve artigo 37, inciso VII. A Lei n.7.783/89 dispõe sobre o exercício do direito de greve dos trabalhadores em geral, afirmado pelo artigo $9^{\circ}$ da Constituição do Brasil. Ato normativo de início inaplicável aos servidores públicos civis. 3. O preceito veiculado pelo artigo 37 , inciso VII, da $\mathrm{CB} / 88$ exige a edição de ato normativo que integre sua eficácia. Reclama-se, para fins de plena incidência do preceito, atuação legislativa que dê concreção ao comando positivado no texto da Constituição. 4. Reconhecimento, por esta Corte, em diversas oportunidades, de omissão do Congresso Nacional no que respeita ao dever, que lhe incumbe, de dar concreção ao preceito constitucional. Pre- 
cedentes. 5. Diante de mora legislativa, cumpre ao Supremo Tribunal Federal decidir no sentido de suprir omissão dessa ordem. Esta Corte não se presta, quando se trate da apreciação de mandados de injunção, a emitir decisões desnutridas de eficácia. 6. A greve, poder de fato, é a arma mais eficaz de que dispõem os trabalhadores visando à conquista de melhores condições de vida. Sua autoaplicabilidade é inquestionável; trata-se de direito fundamental de caráter instrumental. 7. A Constituição, ao dispor sobre os trabalhadores em geral, não prevê limitação do direito de greve: a eles compete decidir sobre a oportunidade de exercê-lo e sobre os interesses que devam por meio dela defender. Por isso a lei não pode restringi-lo, senão protegê-lo, sendo constitucionalmente admissíveis todos os tipos de greve. 8. Na relação estatutária do emprego público não se manifesta tensão entre trabalho e capital, tal como se realiza no campo da exploração da atividade econômica pelos particulares. Neste, o exercício do poder de fato, a greve, coloca em risco os interesses egoísticos do sujeito detentor de capital - indivíduo ou empresa que, em face dela, suporta, em tese, potencial ou efetivamente redução de sua capacidade de acumulação de capital. Verifica-se, então, oposição direta entre os interesses dos trabalhadores e os interesses dos capitalistas. Como a greve pode conduzir à diminuição de ganhos do titular de capital, os trabalhadores podem em tese vir a obter, efetiva ou potencialmente, algumas vantagens mercê do seu exercício. O mesmo não se dá na relação estatutária, no âmbito da qual, em tese, aos interesses dos trabalhadores não correspondem, antagonicamente, interesses individuais, senão o interesse social. A greve no serviço público não compromete, diretamente, interesses egoísticos do detentor de capital, mas sim os interesses dos cidadãos que necessitam da prestação do serviço público. 9. A norma veiculada pelo artigo 37, VII, da Constituição do Brasil reclama regulamentação, a fim de que seja adequadamente assegurada a coesão social. 10. A regulamentação do exercício do direito de greve pelos servidores públicos há de ser peculiar, mesmo porque "serviços ou atividades essenciais" e "necessidades inadiáveis da coletividade" não se superpõem a "serviços públicos"; e vice-versa. 11. Daí porque não deve ser aplicado ao exercício do direito de greve no âmbito da Administração tão-somente o disposto na Lei n.7.783/89. A esta Corte impõe-se traçar os parâmetros atinentes a esse exercício. 12. O que deve ser regulado, na hipótese dos autos, é a coerência entre o exercício do direito de greve pelo servidor público e as condições necessárias à coesão e interdependência social, que a prestação continuada dos serviços públicos assegura. 13. O argumento de que a Corte estaria então a legislar - o que se afiguraria inconcebível, por ferir a independência e harmonia entre os poderes (art. $2^{\circ}$ da Constituição do Brasil) e a separação dos poderes ( $\left.\operatorname{art} .60, \mathfrak{S} 4^{\circ}, \mathrm{III}\right)$ - é insubsistente. 14. O Poder Judiciário está vinculado pelo dever-poder de, no mandado de injunção, formular supletivamente a norma regulamentadora de que carece o ordenamento jurídico. 15. No mandado de injunção o Poder Judiciário não define norma de decisão, mas enuncia o texto normativo que faltava para, no caso, tornar viável o exercício do direito de greve dos servidores públicos. 16. Mandado de injunção julgado procedente, para remover o obstáculo decorrente da 
omissão legislativa e, supletivamente, tornar viável o exercício do direito consagrado no artigo 37, VII, da Constituição do Brasil.

Percebe-se, portanto, que atualmente o direito de greve está assegurado ao servidor público por expressa intervenção do Supremo Tribunal Federal, que determinou a aplicação da lei válida para o setor privado, com algumas adaptações, enquanto o Congresso Nacional não cumprir a sua obrigação de regulamentar o tema. É de lamentar que mesmo após decorridos seis anos da decisão os nossos parlamentares ainda não tenham aprovado essa lei: ao que parece, admitiram deixar como está.

Afinal, são distintas as funções judiciária e legislativa, sendo certo que no caso do instrumento processual do mandado de injunção o Poder Judiciário não legisla, mas apenas normatiza: "Sua função aqui é meramente supletiva. Atua porque o legislador não atuou. E não impede que ele atue depois. Daí a correta distinção entre função legislativa, própria do legislador eleito e função normativa, de natureza supletiva, exercida complementarmente pelo Judiciário" (Silva, 2008, p.126).

E existe ainda muito espaço para legislar, com o objetivo de introduzir em nosso ordenamento mecanismos mais efetivos de negociação coletiva no setor público. Afinal, de que vale assegurar o direito de greve ao servidor público sem que a Administração se sinta obrigada a negociar?

Estudo publicado pelo Dieese em maio de 2013, com o balanço das greves de 2012, traz alguns dados que saltam aos olhos: foram pesquisadas 873 paralisações, sendo 461 no setor privado (53\%) e 409 no setor público (47\%). Em termos da quantidade de horas paradas, foram 21,2 mil no setor privado contra 65,4 mil no setor público; já quanto à duração das greves, $30 \%$ foram de um dia, $60 \%$ de até cinco dias, e $11,6 \%$ se prolongaram por mais de trinta dias. Essas greves mais prolongadas foram 101 no total, e a grande maioria (87) aconteceu na esfera pública.

Vale dizer, são dados que revelam a maior dificuldade do setor público em lidar com os movimentos grevistas, fazendo que as paralisações se prolonguem no tempo, tendo em vista a resistência do administrador público em negociar com os trabalhadores.

Considerando que a greve é um direito individual do trabalhador, mas de exercício coletivo declarado pelo sindicato, uma providência que se afigura imprescindível para o aperfeiçoamento do modelo brasileiro de relações de trabalho é a inclusão, no ordenamento jurídico, de mecanismos efetivos de proteção contra os atos antissindicais.

O Brasil não tem uma legislação que se aprofunde nesse tema, visando dar legitimidade ao processo de negociação coletiva: sendo assim, não basta falar da necessidade de uma reforma sindical para buscar atribuir maior representatividade aos sindicatos, mas é necessário ir mais além e estabelecer garantias para o livre exercício da sua atividade. 
São classificados como antissindicais quaisquer atos que venham a prejudicar indevidamente o titular de direitos sindicais, quando em exercício de atividade sindical.

Mostra-se necessário identificar os atos jurídicos que produzem efeitos danosos na órbita da liberdade sindical (individual ou coletiva, positiva ou negativa, organizacional ou de ação sindical), de forma a propiciar interpretações ampliativas de conteúdo para aquelas condutas, como acontece com os ilícitos civis (Martinez, 2013, p.209).

O sujeito prejudicado tanto pode ser um indivíduo quanto o próprio sindicato; como exemplos, podem ser citados atos como: (i) a despedida injusta de dirigente sindical; (ii) a proibição de distribuição de material informativo do sindicato na porta do estabelecimento; (iii) a repressão a manifestações pacíficas; ou (iv) as atitudes e ameaças do empregador que visem desencorajar os empregados de se filiarem ao sindicato ou aderirem a um movimento grevista.

Quanto aos agentes, capazes de praticarem tais atos, podem ser arrolados os empregadores e seus prepostos, as organizações de empregadores e até mesmo o Estado (este, tanto no seu papel de empregador quanto no de autoridade administrativa).

A ideia de que o direito deve coibir certas "práticas desleais" surge com a lei nacional de relações de trabalho dos Estados Unidos da América, de 1935, conhecida como "Lei Wagner", que proíbe determinadas condutas dos empregadores ("unfair labour practices"), tais como: obstrução do exercício de direitos sindicais, atos de ingerência dos empregadores nas associações de trabalhadores, certos atos discriminatórios e a negativa de promover a negociação coletiva.

Posteriormente, uma outra lei, de 1947, conhecida como "Lei Taft-Hartley", bilateralizou as práticas desleais (que antes só estavam previstas para o setor patronal), para qualificar como desleais também determinados atos cometidos pelas organizações sindicais de trabalhadores, relacionados principalmente com o uso da violência, da intimidação, da represália, da negativa de negociar.

A Organização Internacional do Trabalho (OIT) expressa a sua preocupação quanto à necessidade de repressão aos atos antissindicais, prevendo mecanismos de proteção contra o que chama de atos de "discriminação" e de "ingerência".

O conceito de "atos de discriminação" está previsto no artigo $1^{\circ}$ da Convenção n.98 da OIT, de 1949:

Os trabalhadores gozarão de adequada proteção contra atos de discriminação com relação a seu emprego. Essa proteção aplicar-se-á especialmente a atos que visem: a) sujeitar o emprego de um trabalhador à condição de que não se filie a um sindicato ou deixe de ser membro de um sindicato; b) causar a demissão de um trabalhador ou prejudicá-lo de outra maneira por sua filiação a um sindicato ou por sua participação em atividades sindicais fora das horas 
de trabalho ou, com o consentimento do empregador, durante o horário de trabalho.

Já a noção de “atos de ingerência” está prevista no artigo $2^{\circ}$ da Convenção n.98 da OIT:

As organizações dos trabalhadores e dos empregadores gozarão de adequada proteção contra atos de ingerência de umas nas outras, ou por agentes ou membros de umas nas outras, na sua constituição, funcionamento e administração. Serão considerados atos de ingerência, nos termos deste artigo, promover a constituição de organizações de trabalhadores dominadas por organizações de empregadores ou manter organizações de trabalhadores com recursos financeiros ou de outra espécie, com o objetivo de sujeitar essas organizações ao controle de empregadores ou de organizações de empregadores.

Em suma, a proteção contra os atos antissindicais pode ser entendida como toda medida tendente a evitar, reparar ou sancionar qualquer ato que prejudique indevidamente o trabalhador ou as organizações sindicais no exercício da atividade sindical, ou ainda qualquer ato que lhes negue injustificadamente as facilidades ou prerrogativas necessárias para o normal desenvolvimento da ação coletiva (Ermida Uriarte, 1987, p.9-19).

A previsão de uma sanção penal para os atos antissindicais é um mecanismo que foi adotado pelo direito italiano com bons resultados: o artigo 28 do Statuto dei Lavoratori autoriza o juiz a punir o autor de ato considerado antissindical, por meio de um procedimento especial que se caracteriza pela celeridade processual, representando uma coação indireta ao cumprimento de ordens judiciais, exaradas com o objetivo de cessar um comportamento antissindical (Giugni, 1991, p.119; Galantino, 1996, p.114-28).

Lembre-se ainda que o Código Civil brasileiro consagra a boa-fé como princípio que deve reger a conclusão e a execução do contrato (art. 422), bem como a interpretação dos negócios jurídicos (art. 113), de tal maneira que é indispensável sua presença na negociação coletiva de trabalho, como mecanismo de preservação da higidez da atividade sindical.

Mas não é só!

Para encerrar esta reflexão sobre o exercício do direito de greve cabe ainda mencionar o Código de Ética da USP (aprovado pela Resolução n.4.871, de 22 de outubro de 2001), que se destina a nortear as relações humanas no âmbito da Universidade de São Paulo, tendo como postulados o direito à pesquisa, o pluralismo, a tolerância, a autonomia em relação aos poderes políticos, o respeito à integridade acadêmica da instituição, bem como o dever de promover os princípios de liberdade, justiça, dignidade humana, solidariedade e a defesa da USP como universidade pública.

São princípios na ação da Universidade: (i) a não adoção de preferências ideológicas, religiosas, políticas, e raciais, bem como quanto ao sexo e à origem; 
(ii) a não adoção de posições de natureza partidária; (iii) a não submissão a pressões de ordem ideológica, política ou econômica que possam desviar a Universidade de seus objetivos científicos, culturais e sociais.

O Código também estabelece como garantias nas relações entre os membros da Universidade: (i) o intercâmbio de ideias e opiniões, sem preconceitos ou discriminações entre as partes envolvidas; (ii) o direito à liberdade de expressão dentro de normas de civilidade e sem quaisquer formas de desrespeito.

Interessante destacar o artigo $6^{\circ}$ do Código de Ética, quando prevê que constitui dever funcional e acadêmico dos membros da Universidade "promover a melhoria das atividades desenvolvidas pela Universidade, garantindo sua qualidade" (inciso V) e "preservar o patrimônio material e imaterial da Universidade e garantir o reconhecimento da autoria de qualquer produto intelectual gerado no âmbito de suas Unidades e órgãos" (inciso VIII).

Já o artigo $8^{\circ}$ estabelece que as relações entre os servidores devam ser pautadas pelo respeito recíproco, espírito de colaboração e solidariedade e reconhecimento da igual responsabilidade perante a Universidade; e o artigo $9^{\circ}$ prevê que a posição hierárquica ocupada por servidores não poderá ser utilizada para: (i) desrespeitar ou discriminar subordinados; (ii) criar situações embaraçosas ou desencadear qualquer tipo de perseguição ou atentado à dignidade da pessoa humana.

Por fim, necessário registrar ainda a regra do artigo 15 , inciso IV, segundo a qual cabe ao docente "empenhar-se na defesa da dignidade da profissão docente e de condições de trabalho e remuneração compatíveis com o exercício e aprimoramento da profissão".

Vale dizer, todos esses dispositivos, criados para regular a convivência entre os membros da comunidade acadêmica, devem ser invocados para inspirar a atuação de todos os envolvidos nos episódios de greves - como dirigentes, professores, servidores ou estudantes.

Enfim, o que podemos concluir com esta breve análise do tema é que o Brasil ainda precisa avançar no aperfeiçoamento de nosso modelo de relações coletivas de trabalho, mas a Universidade de São Paulo tem muito a colaborar nesse debate, respeitando e garantindo internamente o exercício do direito de greve, em consonância com o seu Código de Ética e com os princípios constitucionais aplicáveis.

\section{Referências}

DIEESE. Estudos e pesquisas. Balanço das greves em 2012, n.66, maio de 2013. Disponível em: <www.dieese.org.br>.

ERMIDA URIARTE, O. La protección contra los actos antisindicales. Montevideo: Fundación de Cultura Universitaria, 1987.

GalANTINO, L. Diritto Sindacale. Torino: G. Giappichelli Ed., 1996. 
GIUGNI, G. Diritto Sindacale. Bari: Cacucci Ed., 1991.

MARTINEZ, L. Condutas antissindicais. São Paulo: Saraiva, 2013.

NASCIMENTO, A. M. Curso de Direito do Trabalho. São Paulo: Saraiva, 1992.

SILVA, A. A. da. Greve no serviço público depois da decisão do STF. São Paulo: LTr, 2008.

RESUMO - O direito de greve está garantido na Constituição brasileira e foi regulamentado por lei para o setor privado. Diante da omissão do Congresso Nacional acerca do exercício do direito no setor público, o Supremo Tribunal Federal determinou a aplicação, com adaptações, da lei prevista para o setor privado. A Universidade pública pode colaborar no aperfeiçoamento do modelo brasileiro de relações coletivas de trabalho, respeitando e garantindo internamente o exercício do direito de greve, em consonância com o seu código de ética e com os princípios constitucionais aplicáveis.

PALAVRAS-CHAVE: Direito de greve, Ética, Universidade pública, Negociação coletiva.

ABSTRACT - The right to strike is ensured by the Brazilian Constitution and was regulated by law for the private sector. In view of Congress' failure to regulate this right for the public sector, the Supreme Court ruled that the same law for the private sector should be applied, with adaptations. Public universities may contribute to improve the Brazilian model of collective labor relations, internally respecting and ensuring the exercise of the right to strike, in keeping with their code of ethics and with applicable constitutional principles.

KErWORDs: Right to strike, Ethics, Public university, Collective bargaining.

Otavio Pinto e Silva é professor associado da Faculdade de Direito, Universidade de São Paulo. @- otavio_pinto@uol.com.br / otavio@siqueiracastro.com.br

Recebido em 5.12.2013 e aceito em 31.1.2014.

I Faculdade de Direito, Universidade de São Paulo, São Paulo/SP, Brasil. 
